\title{
A guarda da memória do cuidado em saúde como direito da humanidade
}

\author{
Keeping the memory of health care as a human right
}

\section{La conservación de la memoria del cuidado de la salud como un derecho humano}

\author{
Angélica Baptista Silva ${ }^{1, a}$ \\ angelica.baptista@fiocruz.br | https://orcid.org/0000-0003-0292-5106
}

\begin{abstract}
${ }^{1}$ Fundação Oswaldo Cruz, Escola Nacional de Saúde Pública Sergio Arouca, Departamento de Direitos Humanos, Saúde e Diversidade Cultural. Rio de Janeiro, RJ, Brasil.
\end{abstract}

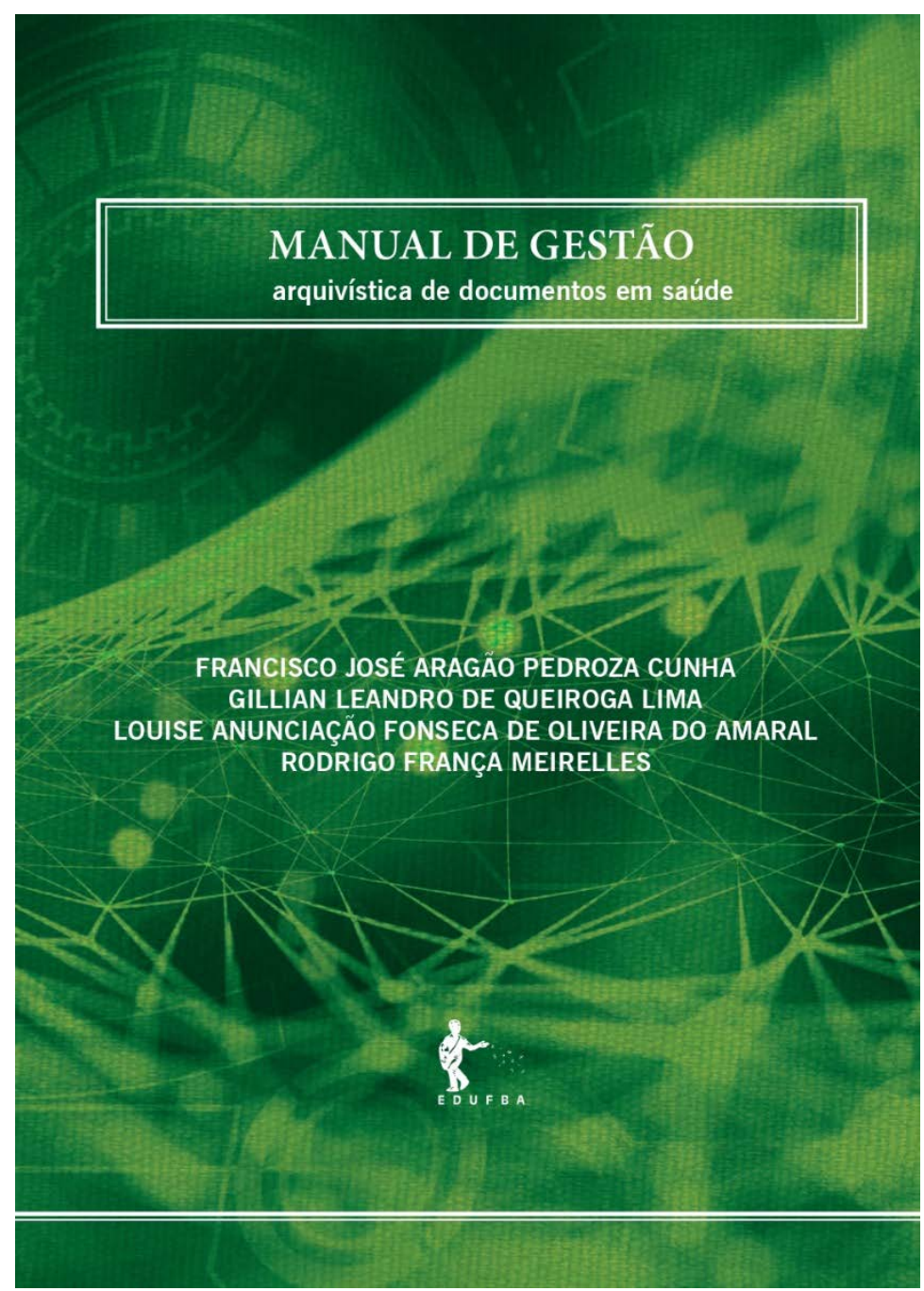




\section{RESUMO}

A resenha do Manual de Gestão Arquivística de Documentos em Saúde apresenta o tema do livro e a sua importância para a saúde global. O direito do paciente, os problemas da digitalização e a guarda da memória dos prontuários ganharam uma nova perspectiva com a informatização da assistência à saúde. Considerase uma contribuição aos direitos humanos no campo da saúde garantir a cadeia de custódia dos registros, prevista na legislação e nos procedimentos recomendados pelo Conselho Nacional de Arquivos no Brasil.

Palavras-chave: Direitos humanos; Saúde global; Comunicação em saúde; Registros eletrônicos de saúde; Armazenamento e recuperação da informação.

\section{ABSTRACT}

The review of Manual de Gestão Arquivística de Documentos em Saúde (Manual of Archival Management of Health-Related Documents) presents the book's theme and its importance for global health. The patient's right, the problems of digitizing and the keeping of the memory of medical records gained a new perspective with the informatization of health care. It is a contribution to human rights in health to guarantee the chain of custody of documents, provided for in the legislation and procedures recommended by the National Council of Archives in Brazil.

Keywords: Human rights; Global health; Health communication; Electronic health records; Information storage and retrieval.

\section{RESUMEN}

La revisión del Manual de Gestão Arquivística de Documentos em Saúde (Manual de Gestión de Documentos de Archivo en Salud) presenta el tema del libro y su importancia para la salud global. El derecho del paciente, los problemas de digitalización y el mantenimiento de la memoria de las historias clínicas adquirieron una nueva perspectiva con la informatización de la atención en salud. Es una contribución a los derechos humanos en salud para garantizar la cadena de custodia de documentos, prevista en la legislación y en los procedimientos recomendados por el Consejo Nacional de Archivos de Brasil.

Palabras clave: Derechos humanos; Salud global; Comunicación en salud; Registros electrónicos de salud; Almacenamiento y recuperación de la información.

Obra resenhada: CUNHA, Francisco José Aragão Pedroza et al. Manual de Gestão Arquivística de Documentos em Saúde. Salvador: EdUfba, 2021.

Contribuição dos autores: a autora é responsável por todo texto.

Declaração de conflito de interesses: não há.

Fontes de financiamento: não houve.

Considerações éticas: não há.

Agradecimentos/Contribuições adicionais: não há.

Histórico do artigo: submetido: 03 fev. 2022 | aceito: 03 fev. 2022 | publicado: 25 fev. 2022.

Apresentação anterior: não houve.

Licença CC BY-NC atribuição não comercial. Com essa licença é permitido acessar, baixar (download), copiar, imprimir, compartilhar, reutilizar e distribuir os artigos, desde que para uso não comercial e com a citação da fonte, conferindo os devidos créditos de autoria e menção à Reciis. Nesses casos, nenhuma permissão é necessária por parte dos autores ou dos editores. 
Em tempo de apagão de dados no território brasileiro, como guardar com segurança os documentos que registram o cuidado à população? Essa é uma indagação que tomou contornos dramáticos com a chegada da pandemia de SARS-CoV-2, que em 2022 completa dois anos de existência, reconfigurando os serviços de saúde e como são concebidas a ciência e a inovação.

Podemos delinear algumas respostas com uma observação atenta. Uma questão é pensar sobre a natureza da informação em saúde. Vamos pensar nas informações que circulam em rede: as informações que passamos e metrificamos sobre os nossos gostos e as nossas preferências mercadológicas diferem daquelas sobre os nossos corpos, sobre como adoecemos e morremos. É disso que trata o Manual de Gestão Arquivística de Documentos em Saúde (GADS).

A pesquisa translacional em saúde, que alia o conceito de pesquisa aplicada - essa que já começa voltada a um produto para a sociedade - e o imediatismo das aplicações da inovação, estimulado pelo crescimento das empresas de biotecnologia, contribuiu para um novo cenário nos serviços da assistência à saúde (SILVA; MOREL; MORAES, 2014). Nesse sentido, o Manual de Gestão Arquivística de Documentos em Saúde aborda um ponto muito relevante e necessário: o manual de Francisco Cunha e colaboradores (2021) questiona como ficarão os arquivos médicos das complexas instituições de saúde sem que se caia num imperativo tecnológico.

Em hospitais de referência e em outros estabelecimentos de saúde que os autores denominam Organismos Produtores de Serviços de Atenção à Saúde (OPSAS), a conservação, o tratamento e a guarda desses documentos ocupava ou ainda ocupa espaço, e esses locais dispunham ou ainda dispõem de uma gama de profissionais para o seu manuseio. Trata-se de agora de uma nova realidade, na qual o profissional e o seu fazer sofreram muito impacto com o advento das tecnologias da informação e da comunicação no mercado de trabalho. No entanto, observa-se um despreparo na cultura organizacional das instituições, tanto no que diz respeito à aquisição de infraestrutura específica como no investimento em recursos humanos para encarar o processo de guarda de documentos mediado por tecnologia.

Nesta publicação, os autores elaboraram uma ferramenta importante de diálogo inicial com o profissional que está em ambiente clínico e precisa cuidar da memória dos arquivos em saúde, sendo eles ainda em papel, nativos digitais ou em processo de digitalização.

A obra tem uma linguagem simples, que já surge na apresentação da publicação, e também exibe uma aparência diferente, posto que a publicação parece um caderno de estudante. Essas características reforçam a intenção dos autores de se aproximar de um público iniciante na arte de cuidar de um grande conjunto de documentos, manuseável por diversos profissionais e com uma importância ímpar tanto legal quanto clínica - um testemunho do trabalho da equipe na assistência ao paciente (BERG; BOWKER, 1997).

O contexto de transição para o digital desse material, além de oneroso, precisa resguardar a autenticidade dos documentos clínicos, preconizada pela Lei de Arquivos (FARIAS NETO; QUEIROGA; CUNHA, 2018). Essa passagem implica uma aceitação e um constante diálogo com a equipe multidisciplinar clínica e administrativa, a elaboração de procedimentos operacionais padrões (POP) novos, que esclareçam as mudanças de fluxos e processos em relação à documentação digital do cuidado, esta denominada por alguns autores como Registro Eletrônico de Saúde (RES) (SILVA et al., 2019).

Os Sistemas de Registro Eletrônico de Saúde (S-RES), tipos de sistemas de informação em saúde, embarcados em instituições de diversos níveis de complexidade nas redes de atenção à saúde, têm certamente três nós górdios: o repositório digital; a interoperabilidade desse sistema com a rede ou com outros S-RES isoladamente; e a adequação à legislação de proteção de dados. Esses nós, que serão desatados com a construção participativa de uma Política de Governança da Informação, terão de envolver todos os agentes de tratamento de dados da instituição (ABRASCO, 2021; BRASIL, 2018) com o auxílio inestimável do arcabouço teórico e da produção de conhecimento acumulada da arquivologia. 
Quanto ao primeiro nó que abordarei nesta resenha - o repositório digital -, trata-se de um dos focos do manual em questão: para a consolidação de um repositório que mantenha a fidedignidade da documentação, é preciso citar algumas tecnologias associadas. A nuvem e as tecnologias de blockchain e peer to peer foram estimuladas pelos projetos de criação de criptomoedas, cujo precursor foi o bitcoin. A infraestrutura da internet está no segundo milênio totalmente a serviço da financeirização da vida e do consumo (ZUBOFF, 2019). O senso comum influenciado pelo marketing do Big Money e das Big Techs esquece ou ignora que a nuvem tem sua versão concreta. As salas-cofre que abrigam as nuvens são de alto custo, consomem bastante energia não renovável a serviço de uma circulação monetária, que não gera bem-estar nem distribuição de riqueza para a população global, precarizando ainda mais a vida dos mais vulneráveis.

Com a transição epidemiológica, o grande contingente da população tem uma longevidade maior, criando um grupo com um feixe de doenças crônicas que vem sobrecarregando gradualmente as estruturas dos sistemas de saúde territoriais, de acordo com os especialistas em prospecção (SILVA et al., 2020). Essas estruturas físicas de alto poder de computação e de armazenamento, que já representam aportes e custos para parte de economias nacionais, como ocorre no Cazaquistão (ALBUQUERQUE, 2022), precisam estar a serviço do bem-estar e da qualidade de vida da população com uma política diferenciada, gratuita para instituições de pesquisa e de assistência pública à saúde da população. Os autores da recente publicação dão dicas muito importantes no capítulo em que descrevem a política e a legislação sobre a gestão arquivística no Brasil, que vem detalhada de 1978 a 2015 - uma discussão de quase meio século.

Cabe ressaltar, em tempos de fluidez, o conceito de cidadania (BAUMAN, 2007; LOBATO; FLEURY, 2009), pois o direito do paciente a informações sobre seu histórico registrado no prontuário é um direito humano garantido por uma série de normativas em âmbitos local, nacional e global (ALBUQUERQUE, 2019). Portanto, garantir a cadeia de custódia documental no ecossistema das Tecnologias da Informação e Comunicação (TIC) é colaborar com o acesso a esse direito. Com este manual, o profissional de saúde ganha mais uma ferramenta para proteger o paciente, dar direito ao acesso amplo e irrestrito ao seu prontuário e conscientizar a sociedade em geral dos novos perigos do uso indiscriminado dos seus dados clínicos no mundo digital (SEKALALA et al., 2020), garantindo, dessa maneira, a difusão do conhecimento para as gerações futuras.

Nessa luta biopolítica e tecnológica, resta saber quais serão os vestígios documentais da pandemia do famigerado SARS-CoV-2 em 2122 d.C. Os prontuários digitais auxiliarão os mitigadores das pragas vindouras como os registros da gripe espanhola têm auxiliado nossos especialistas? Quem acordar da criogênese dirá!

\section{REFERÊNCIAS}

ALBUQUERQUE, Aline Oliveira. Pesquisa com prontuário: análise ético-jurídica à luz dos direitos humanos dos pacientes. Cadernos de Ética em Pesquisa, Brasília, DF, v. 1, n. 1, p. 41-59, dez. 2019. Disponível em: https://cadernosdeeticaempesquisa.cienciasus.gov.br/index.php/Caderno19/article/view/12. Acesso em: 03 fev. 2022.

ALBUQUERQUE, Karol. Bitcoin despenca para nível mais baixo em meses. Olhar Digital, [s. I.], 7 jan. 2022. Pro. Disponível em: https://olhardigital.com.br/2022/01/07/pro/bitcoin-despenca-para-nivel-mais-baixo-emmeses/. Acesso em: 27 jan. 2022.

ASSOCIAÇÃO BRASILEIRA DE SAÚDE COLETIVA (ABRASCO). $3^{\circ}$ plano diretor para o desenvolvimento da informação e tecnologia de informação em saúde: $3^{\circ}$ PlaDITIS 2020-2024. Rio de Janeiro: Associação Brasileira de Saúde Coletiva, 2021. Disponível em: https://www.abrasco.org.br/ site/gtinformacoesemsaudeepopulacao/wp-content/uploads/sites/13/2021/04/plad5.pdf. Acesso em: 03 fev. 2022.

BAUMAN, Zygmunt. Tempos líquidos. Tradução de Carlos Alberto Medeiros. Rio de Janeiro: Jorge Zahar, 2007. 
BERG, Marc; BOWKER, G. The multiple bodies of the medical record: toward a Sociology of an artifact. Sociological Quarterly, [s. I.], v. 38, n. 3, p. 513-537, 1997. Disponível em: http://www.jstor.org/ stable/4121157 Acesso em: 03 fev. 2022.

BRASIL. Presidência da República. Secretaria-Geral; Subchefia para Assuntos Jurídicos. Lei n 13.709, de 14 de agosto de 2018. Dispõe sobre a proteção de dados pessoais e altera a lei n 12.965, de 23 de abril de 2014 (Marco Civil da Internet). Diário Oficial da União, Brasília (DF), n. 157, p. 59, 15 ago. 2018. Seção 1. Disponível em: http://www.planalto.gov.br/ccivil 03/ ato2015-2018/2018/lei/l13709.htm. Acesso em: 03 fev. 2022.

FARIAS NETO, Luiz Conrado de; QUEIROGA, Gillian; CUNHA, Francisco José Aragão Pedroza. Pontos de convergência entre as políticas de informação em saúde e a arquivologia: a gestão de documentos no $2^{\circ}$ PlaDITIS para as inovações nos serviços de saúde. Archeion Online, João Pessoa, v. 6, n. 1, p. 96-111, 2018. DOI: https://doi.org/10.22478/ufpb.2318-6186.2018v6n1.38760. Disponível em: https://periodicos.ufpb.br/ ojs/index.php/archeion/article/view/38760. Acesso em: 03 fev. 2022.

LOBATO, Lenaura de Vasconcelos Costa; FLEURY, Sonia. Seguridade social, cidadania e saúde. Rio de Janeiro: Centro Brasileiro de Estudos de Saúde, 2009. (Coleção Pensar em Saúde). Disponível em: https:// cebes.org.br/site/wp-content/uploads/2013/10/Livro_Seguridade.pdf. Acesso em: 05 fev. 2022.

SEKALALA, Sharifah et al. Analyzing the human rights impact of increased digital public health surveillance during the covid-19 crisis. Health and Human Rights, Boston, v. 22, n. 2, p. 7-20, dez. 2020. Disponível em: https://www.ncbi.nlm.nih.gov/pmc/articles/PMC7762901/. Acesso em: 03 fev. 2022.

SILVA, Angélica Baptista et al. Registro eletrônico de saúde em hospital de alta complexidade: um relato sobre o processo de implementação na perspectiva da telessaúde. Ciência \& Saúde Coletiva, Rio de Janeiro, v. 24, n. 3, p. 1133-1142, mar. 2019. DOI: https://doi.org/10.1590/1413-81232018243.05982017. Disponível em: https://www.scielo.br/j/csc/a/gr8zBQ8x3z3try5XmHCnKqR/abstract/?lang=pt. Acesso em: 03 fev. 2022.

SILVA, Angélica Baptista et al. Three decades of telemedicine in Brazil: Mapping the regulatory framework from 1990 to 2018. PLoS One, São Francisco, v. 15, n. 11, p. e0242869, 25 nov. 2020. DOI: https://doi. org/10.1371/journal.pone.0242869. Disponível em: https://journals.plos.org/plosone/article?id=10.1371/ journal.pone.0242869. Acesso em: 03 fev. 2022.

SILVA, Angélica Baptista; MOREL, Carlos Médicis; MORAES, Ilara Hämmerli Sozzi de. Proposta conceitual de telessaúde no modelo da pesquisa translacional. Revista de Saúde Pública, São Paulo, v. 48, n. 2, p. 347-356, abr. 2014. DOI: https://doi.org/10.1590/S0034-8910.2014048004923. Disponível em: https://www. scielo.br/j/rsp/a/LBxs98XCzVbsw8jsymDXrrN/?lang=pt. Acesso em: 03 fev. 2022.

ZUBOFF, Shoshana. The age of surveillance capitalism: the fight for a human future at the new frontier of power. Londres: Profile Books, 2019. 